\title{
Que sait-on du déterminisme de la qualité des huiles du tournesol face aux nouvelles attentes?
}

\author{
Monique BERGER \\ Alicia AYERDI-GOTOR ${ }^{2}$ \\ Ahmad SARRAFI ${ }^{3}$ \\ Pierre MAURY ${ }^{4}$ \\ Jean DAYDÉ ${ }^{1}$ \\ Anne CALMON ${ }^{5}$ \\ ${ }^{1}$ UMR Inra/EIP 1054-université de Toulouse, \\ École d'ingénieurs de Purpan, Laboratoire \\ d'agrophysiologie, 75, voie du TOEC, BP 57611, \\ 31076 Toulouse cedex 03 France \\ $<$ monique.berger@purpan.fr> \\ ${ }^{2}$ Institut polytechnique LaSalle Beauvais, \\ 19, rue Pierre-Waguet, BP 30313, \\ 60026 Beauvais cedex, France \\ 3 INP-Ensat, IFR 40, \\ Laboratoire de symbiose et pathologie \\ des plantes (SP2), 18, chemin de Borde-Rouge, \\ 31326 Castanet Tolosan, France \\ ${ }^{4}$ Université de Toulouse, \\ INPT, UMR AGIR, ENSAT, \\ 31320 Castanet Tolosan, France \\ ${ }^{5}$ UPSP/DGER 115-université de Toulouse, \\ École d'ingénieurs de Purpan, Laboratoire \\ d'agrophysiologie, 75, voie du TOEC, BP 57611, \\ 31076 Toulouse cedex 03, France
}

Le tournesol est essentiellement cultivé pour son huile, bien qu'une petite partie des graines soit directement consommée en alimentation humaine ou animale. Les graines, ou akènes, du tournesol contiennent de l'ordre de $45 \%$ d'huile, essentiellement utilisée en alimentation humaine mais aussi dans l'industrie, particulièrement pour la production de biocarburants. Après les pays de l'ex-URSS, la France et l'Espagne en sont les principaux consommateurs. L'huile de tournesol contient $98 \%$ d'acides gras et une fraction dite « insaponifiable » composée majoritairement de tocophérols (vitamine E) et de phytostérols. Seule ou combinée à d'autres, c'est une huile capable de répondre à de nombreuses exigences du secteur de l'agroalimentaire. Elle est le plus souvent utilisée comme huile de table pure

\begin{abstract}
Sunflower oil is widely consumed in France and Spain. This oil has a good reputation among consumers, due to its high polyunsaturated fatty acid content. Thirty years after its discovery, the oleic mutation (high C18:1 contents) has now reached agricultural production, with fast increasing surfaces for the last three years. The challenge is now the production of very high oleic (>90\%) sunflowers and new fatty acid profiles, such as high linoleic, palmitic, stearic or stearic + oleic hybrids, which are of high interest for chemistry or food industry. The problem is now the stability of the expression in varying genetic backgrounds, and the understanding of environmental effects. Minor components are also a main strength of sunflower oil: its high tocopherols (Vitamin E) content (0,5 to 1\%) is all the more interesting for nutritionists that they be almost exclusively a-tocopherol (>95\%), which is the most vitaminic active component. Nowadays, the unraveling of tocopherols biosynthesis and its key points of regulation is in progress. New tocopherol profiles have been recently obtained. Higher protective effects are attributed to $\gamma$-or $\delta$-tocopherols. They could increase the stability of oils or margarines. Genetic progress for total content is possible, as in sunflower like in other oilseed crops, heritability is rather high (>0.7). Sunflower oil also contains twice as much phystosterols as olive oil (3 vs 1,5\%), and mainly $\beta$-sitosterol. Major mutations of this pathway can induce penalizing phenotypic modifications: 1) campesterol is the precursor of plant hormones brassinosteroids, and 2) stigmasterol/campesterol ratio is also implied in plant growth regulation. However, hybrids can significantly differ in their total content. Either for fatty acids or minor components, breeding programs for new profiles, or higher contents, need high throughout oil extraction and analysis. Chemometric analysis offer interesting solutions despite their need of large sets of reference analysis.
\end{abstract}

Key words: sunflower oil quality, fatty acids, vitamin $E$, plant sterols

ou en mélange et pour la fabrication d'assaisonnements, de sauces, de margarines où sa composition permet de limiter l'usage de I'hydrogénation, génératrice d'acides gras trans. Sa teneur élevée en tocophérols et en phytostérols apporte un argument santé supplémentaire.

Elle est composée en moyenne de $67 \%$ d'acide linoléique (C18:2), $20 \%$ d'acide oléique (C18:1), $7 \%$ d'acide palmitique (C16:0) et $5 \%$ d'acide stéarique (C18:0), le reste (acides gras mineurs) étant surtout constitué d'acides gras saturés à longue chaîne : acides arachidique (C20:0) ; béhénique (C22:0) et lignocérique (C24:0) (Salas et al., 2005 ; Zheljazkov et al., 2009). Cependant, de nombreux travaux ont montré qu'il était possible de modifier le profil des acides gras et des composés mineurs en utilisant des mutations dans un petit nombre de gènes (Skoric et al., 2008).

\section{Acides gras}

Les acides gras sont stockés sous la forme de triacyglycérols (TAG) : leur synthèse est donc liée à celle du glycérol-3-phosphate (G3P) qui constitue une des étapes limitantes de leur accumulation.

La synthèse des acides gras est initiée à partir de l'acétyl-CoA, précurseur des groupes acétyle constitutifs de la chaîne (figure 1). Celui-ci est transformé en malonyl-CoA par l'acétyl-CoA carboxylase (ACC), transféré sur un cofacteur protéique (ACP ou acyl carrier protein) et utilisé par les 3-kétoacyl ACP synthases (KASI, II et III) 
pour l'allongement de la chaîne. Les carbones sont ainsi ajoutés deux par deux, sous la forme de groupe acétyle, pour obtenir un complexe palmitoyl (C16:0)-ACP ou stéaroyl (C18:0)ACP. À ce stade, ce composé peut être désaturé entre le neuvième et le dixième carbone par une acyldésaturase (AAD1) spécifique, la $\Delta^{9}$ stéaroyl-ACP désaturase, ce qui produira un oléoyl (C18:1)-ACP.

Les complexes sont alors hydrolysés par des fatty acyl thioesterases (FATA ou FATB) qui libèrent les acides gras. Chez le tournesol, trois acides gras (palmitique, stéarique et oléique) sont produits au niveau des plastes. Ils sont ensuite exportés sous forme acyl-CoA vers le cyto- plasme où a eu lieu la synthèse des G3P. La première étape de la formation des triacylglycérides est catalysée sur la membrane du réticulum endoplasmique par la glycérol phosphate acyl transférase (GPAT) : un acide gras est transféré en position sn-1 sur le G3P, donnant l'acide lysophosphatidique (LPA), puis un second acide gras est transféré en position sn-2. Chez les plantes, la lysophosphatidic acid acyl transferase (LPAAT) a une plus grande affinité pour les chaînes insaturées, c'est donc l'acide oléique qui prend cette position. Une phosphatase génère le diacylglycérol (DAG) et celui-ci peut i) produire le TAG si un troisième acide gras est placé en position sn-3 par la diacylglycerol acyltransferase (DGAT), ou ii) être transformé en phosphatidylcholine (PC) si une choline est placée en sn-3 par la choline phosphotransférase (CPT).

$\mathrm{Au}$ niveau de la membrane du réticulum, I'acide oléique placé en sn-2 sur une PC peut subir une nouvelle désaturation par une enzyme membranaire, la FAD2, qui génère un oméga-6 linoléoyl-PC (C18:2). Par la suite, la choline peut être enlevée pour générer un DAG, puis un TAG.

Les acyl-CoA libres dans le réticulum endoplasmique peuvent être allongés pour former des acides gras à très longue chaîne (plus de 18 carbones). Cette réaction est limitée chez le

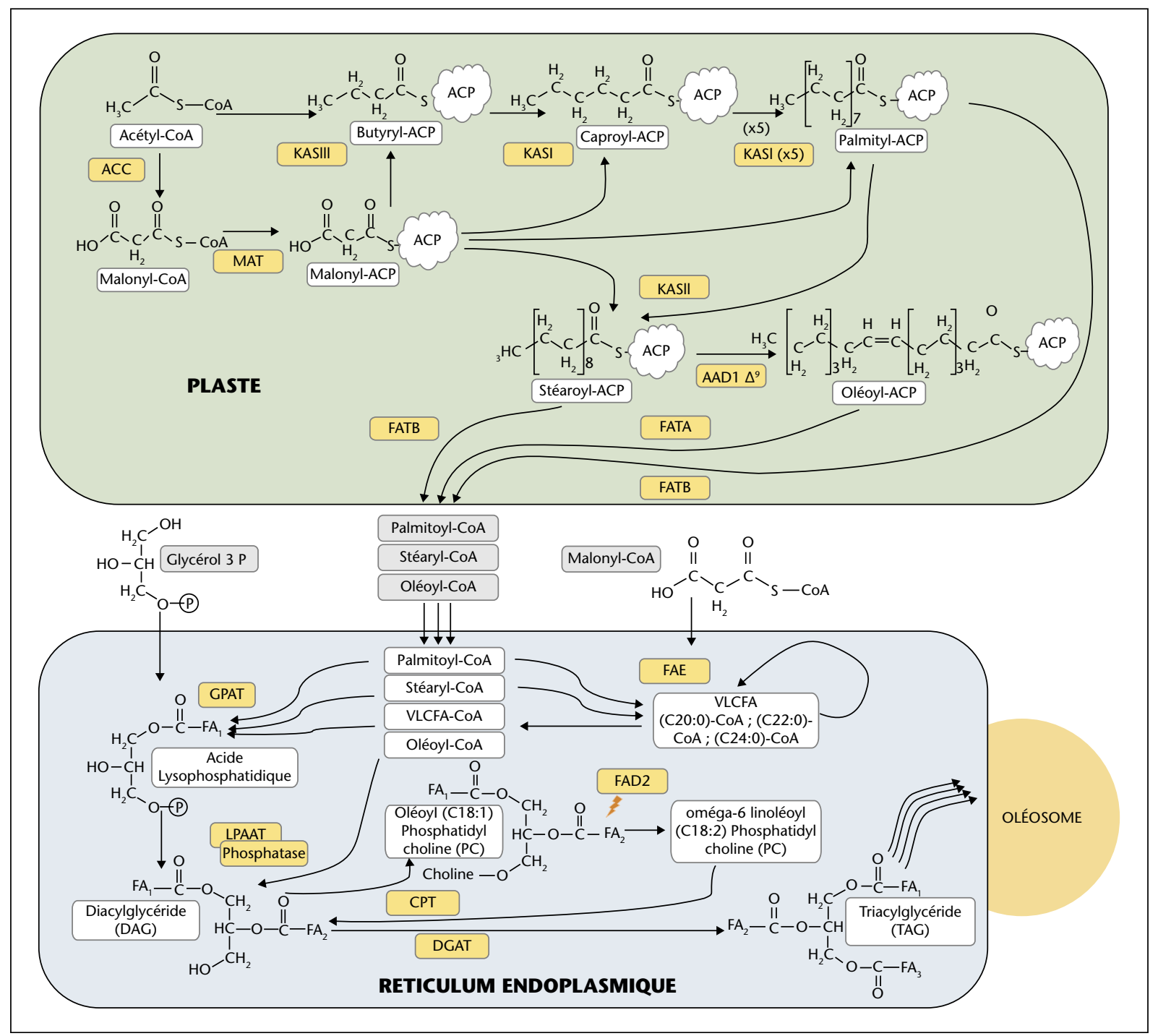

Figure 1. Synthèse des acides gras dans les akènes de tournesol. AAC : acétyl-CoA carboxylase; ACP : acyl carrier protein (transporteur d'acides gras); MAT : malonyl-CoA : ACP-S méthyltransférase; KAS (I, II, III) : kétoacyl-ACP synthases; AAD1 : acido acyl desaturase delta 9 ; FAT : fatty acid thioesterases $A$ pour les acides gras insaturés et $B$ pour les acides gras saturés; GPAT : glycérol phosphate acyl transférase; LPAAT : lysophosphatidic acid acyl transferase ; DGAT : diacyldlycéride acyl transférase ; CPT: CDP-Choline : diacylglycéride phosphotransférase ; FAD2 : oléoyl désaturase; FAE : complexe fatty acids elongase; VLCFA : acides gras à très longues chaînes (> 18 carbones ou very long chain fatty acids). 
tournesol, contrairement aux brassicacées. Le complexe enzymatique mis en jeu est constitué d'enzymes membranaires appelées fatty acid elongases (FAE) (Salas et al., 2005).

Les triacylglycérols sont stockés dans les corps lipidiques, formés par extension de la paroi du réticulum endoplasmique. Ces derniers sont maintenant considérés comme des organites à part entière : les oléosomes (Murphy, 2005 ; Shimada et Hara-Nishimura, 2010 ; Frandsen et al., 2001 ; Baud et Lepiniec, 2010).

Les oléosomes sont observables dans les embryons très tôt, six à sept jours après la fécondation, la synthèse et l'accumulation de lipides peuvent se poursuivre jusqu'à la fin de la croissance de l'embryon (Mantese et al., 2006). Le pic de la lipogenèse a lieu environ trois semaines après la floraison (Lagravere et al., 2004). Chez les variétés à plus faible teneur en huile, I'accumulation de l'huile cesse précocement (Mantese et al., 2006).

\section{Facteurs de variation de la teneur en huile}

Les fortes températures et faibles pluviométries induisent une diminution des teneurs en huile, probablement en provoquant un arrêt prématuré de la lipogenèse (Alpaslan et Gunduz, 2000). Celle-ci est fortement dépendante du flux de carbone qui permet de former les précurseurs de l'acétyl-CoA, mais aussi de fournir l'énergie et le pouvoir réducteur nécessaires grâce à la glycolyse (Weselake et al., 2009). La teneur totale en huile est négativement influencée par la teneur en azote minéral du sol (Zheljazkov et al., 2009). Des modifications de l'assimilation carbonée postfloraison («la source ») conduisent à modifier la masse des grains et leurs concentrations en huile. La masse des grains dépend aussi de l'importance du puits (c'est-à-dire du nombre de grains par plante), pouvant être estimée à partir de l'indice foliaire à la floraison qui traduit la « résultante » de croissance végétative (Mercau et al., 2001). La variabilité au niveau du rendement en huile d'une variété de tournesol pourrait être mieux appréciée (ou expliquée) par la dynamique des relations sources $\times$ puits postfloraison (Ruiz et Maddonni, 2006). Les différences de concentration en huile des graines de tournesol sont ainsi fortement liées à la croissance des différents constituants de l'akène (péricarpe-amande) et à leurs interactions. Le remplissage des graines chez le tournesol, et plus particulièrement l'accumulation des réserves lipidiques au niveau de la graine, est assez bien décrit dans la littérature $d^{\prime} u n$ point de vue analytique (Mantese et al., 2006), mais il existe de fortes interactions entre les variétés, l'environnement et la conduite culturale.

\section{Variabilité des profils}

Le tournesol transforme naturellement une grande partie de son acide oléique en acide linoléique. La désaturase (FAD2) impliquée est sensible à la chaleur. En effet, la régulation de la fluidité des acides gras dans la cellule et les membranes se fait en ajustant le taux de désaturation des lipides : à température élevée, elle doit être plus faible qu'à température basse. L'activité FAD2 est ralentie par l'augmentation de la température. De nombreux travaux ont montré une augmentation de la teneur en acide oléique avec la température cumulée durant le pic d'activité de la lipogenèse (Alpaslan et Gunduz, 2000 ; Roche et al., 2006 ; Baud et Lepiniec, 2010).

La mutation oléique dominante, obtenue dans la population Pervenets par Soldatov en 1976, est une mutation supprimant l'activité FAD2 suite à une duplication du gène qui produit un phénomène de silencing (Lacombe et al., 2009), cependant une activité subsiste puisque les tournesols high oléiques $(\mathrm{HO})$ synthétisent toujours au moins $5 \%$ d'acide linoléique (Lagravere et al., 2004). En fait, l'activité FAD2 chez le tournesol est assurée par une famille d'au moins trois gènes dont un seul, spécifiquement exprimé dans la graine, est inhibé par la mutation Pervenets. Cette mutation dominante s'exprime uniquement dans la graine et semble fortement modulée par le fond génétique. Ainsi, en combinant sélection et pratique culturale, les variétés portant la mutation peuvent produire de 70 à plus de $90 \%$ d'acide oléique (Izquierdo et Aguirrezabal, 2008).

Pour les besoins de l'industrie, la production de tournesol présentant d'autres profils est aussi étudiée (Perez-Vich et al., 2002a ; Perez-Vich et al., 2002b; Salas et al., 2007). On peut ainsi trouver des mutants produisant jusqu'à $37 \%$ d'acide stéarique (Fernandez-Moya et al., 2002) ou 30 à $35 \%$ d'acide palmitique (Serrano-Vega et al., 2005). Les phénotypes high stéariques sont dus à la combinaison de deux modifications d'activité enzymatique: une réduction ou une inhibition de l'activité, la $\Delta^{9}$-stéaroyl-ACP désaturase accompagnée d'une augmentation de l'activité (FATB) qui libère les acides gras de leur transporteur protéique (Cantisan et al., 1999). Une réduction de I'activité KASII liée à une augmentation de l'activité FATB est impliquée dans les phénotypes high palmitique (Serrano-Vega et al., 2005). La combinaison des deux caractères « high » oléique et stéarique serait d'un grand intérêt pour l'industrie en produisant des lignées à forte teneur en acides gras saturés, autres que l'acide palmitique soupçonné $d^{\prime}$ avoir une action néfaste sur la santé. Actuellement, malgré une corrélation génétique négative (Perez-Vich et al., 2002a), les meil- leures combinaisons de mutants sont arrivées à un profil $25 \%$ stéarique/62 \% oléique (Pleite et al., 2006). Enfin, plusieurs mutations auraient permis d'obtenir des lignées présentant jusqu'à $80 \%$ d'acide linoléique (Skoric et al., 2008). La modification des teneurs en acides gras à longues chaînes semble plus difficile : chez le tournesol, les FAE sont fortement rétro-inhibées par leur substrat (Salas et al., 2005).

\section{Influence de l'environnement sur les profils d'acide gras}

De nombreux auteurs ont mis en évidence une baisse de la teneur en acide stéarique lorsque les températures augmentent, et cela autant chez les lignées classiques que chez les high stéariques. Cependant, ce phénomène est moins général que celui qui touche la production d'acide oléique, puisqu'une mutation dont le comportement est inverse a été décrite (Fernandez-Moya et al., 2002). Le comportement de ces mutations est fortement influencé par le fond génétique des lignées dans lesquelles elles sont introduites. Un important travail reste encore à faire pour évaluer la stabilité de ces expressions selon les hybrides et les conditions environnementales fréquemment rencontrées dans les grandes zones de culture du tournesol: fortes températures, forts éclairements et stress hydrique.

L'étude de lignées recombinantes issues d'un croisement entre deux lignées classiques et présentant une forte transgression pour les profils $d^{\prime}$ acides gras a permis de mettre en évidence des QTL spécifiques aux situations environnementales (stress hydrique vs irrigué) ou communs aux différentes conditions de culture (Ebrahimi et al., 2008).

\section{Composés mineurs}

L'huile de tournesol bénéficie d'une bonne image, en raison de sa composition équilibrée en acides gras insaturés, cependant sa trop forte teneur en acides gras oméga- 6 pourrait la désavantager pour une utilisation principale en alimentation, car notre alimentation est déjà déséquilibrée en faveur des oméga-6 (Blouin et al., 2006). Un nouvel intérêt pour cette huile pourrait provenir de sa grande richesse en composés mineurs, notamment en tocophérols (vitamine $\mathrm{E}$ ), intéressants tout autant pour leur effet santé (Colombo, 2010) que pour leur action antirancissement de l'huile (Seppanen et al., 2010). Les phytostérols sont aussi présents en quantité importante. Par leur activité hypocholestérolémiante reconnue (Demonty et al., 2009), ils apportent une bonne plus-value qualitative à I'huile de 
tournesol. Ainsi, impulsés par l'émergence du concept "aliments-santé », et par une demande croissante en direction de produits $d^{\prime}$ origine naturelle et hautement renouvelables, les efforts de recherche et de développement sur la fraction insaponifiable de l'huile se sont multipliés au cours des dernières années. À l'heure actuelle, lors du raffinage de l'huile brute et plus précisément à partir du distillat de désodorisation, les phytostérols sont extraits et purifiés pour être valorisés (Fernandes et Cabral, 2007). La fraction tocophérolique est quant à elle valorisée dans l'huile raffinée; cependant, sa teneur est étroitement liée au processus de raffinage avec des pertes allant de 25 à $75 \%$ (Tasan et Demirci, 2005), mais également aux conditions de stockage (Verleyen et al., 2002).

\section{Tocophérols}

Les tocophérols désignent un ensemble de molécules composées d'un noyau 2-méthyl6-chromanol et d'une chaîne latérale de 16 atomes de carbone saturée en C2 (DellaPenna et Pogson, 2006). La chaîne carbonée existe sous deux formes: une forme comprenant trois insaturations qui caractérise les tocotriénols et une forme totalement saturée pour les tocophérols. Pour chacune de ces catégories, on trouve quatre composés $(\alpha, \beta, \gamma$ et $\delta$ ) selon la position des substitutions méthyl en $\mathrm{C} 5, \mathrm{C} 7$ et C8 de l'anneau aromatique (figure 2). L'ensemble constitue les tocochromanols.

\section{Biosynthèse}

Les tocochromanols sont synthétisés uniquement dans les organismes photoautotrophiques (plantes et microalgues) par l'union de deux composés issus de deux voies métaboliques différentes : la chaîne prényl latérale (phytyldiphosphate [PDP] ou géranylgénranyl diphosphate [GGDP]), produite par la voie de biosynthèse des isoprénoïdes, et le noyau chromanol (acide homogentisique ou HGA), issu de la voie du shikimate (DellaPenna et Pogson, 2006 ; Mene-Saffrane et DellaPenna, 2010).

Cette catalyse est assurée par une homogentisate phytyltransférase (HPT), la fonction HGGT peut être assurée par la même enzyme, bien que la fonction spécifique ait été isolée chez certains végétaux (Falk et Munne-Bosch, 2010). On obtient alors le 2-méthyl-6phytylbenzoquinone (MPBQ), précurseur commun des quatre formes $\alpha, \beta$, $\gamma$ et $\delta$. II peut subir une méthylation supplémentaire en R2 et donne alors 2,3-diméthyl-6-phytylplastoquinol (DMPBQ), et la synthèse des tocophérols est alors divisée en deux voies: ces composés seront à l'origine soit du $\delta$ - (précurseur $\mathrm{MPBQ}$ ), soit du $\gamma$ - (précurseur DMPBQ) tocophérol. Ces formes $\delta$ ou $\gamma$ peuvent alors être à nouveau méthylées en position R1 (par la $\gamma$-méthyltransférase) pour donner respectivement les formes $\beta$ ou $\alpha$. Cette dernière est finalement la forme la plus hautement méthylée (DellaPenna et Pogson, 2006) (figure 3).

Très probablement, les $\gamma$ - et les $\delta$-tocophérols sont synthétisés via la même cyclase (VTE1). Parallèlement, la méthylation finale qui donne les formes $\alpha$ et $\beta$ - tocophérols pourrait être catalysée par là même tocophérol méthyl transférase (VTE4) (Hofius et Sonnewald, 2003 ; DellaPenna et Pogson, 2006).

\section{Intérêt pour la santé}

Parmi les huit molécules composant le groupe des tocochromanols, seul I' $\alpha$-tocophérol est transporté dans la cellule, et les animaux ne peuvent pas faire d'interconversion des différents tocophérols (Traber, 2007). La synthèse chimique de l'a-tocophérol (Chenevert et Courchesne, 2002) est possible à partir des autres formes, mais cette synthèse produit un mélange racémique de huit stéréoisomères; c'est ce mélange qui est vendu comme complément vitaminique $E$. Les transporteurs membranaires ne reconnaissent que la seule forme RRR $\alpha$-tocophérol. L'activité vitaminique réelle est donc stricto sensu due à cette

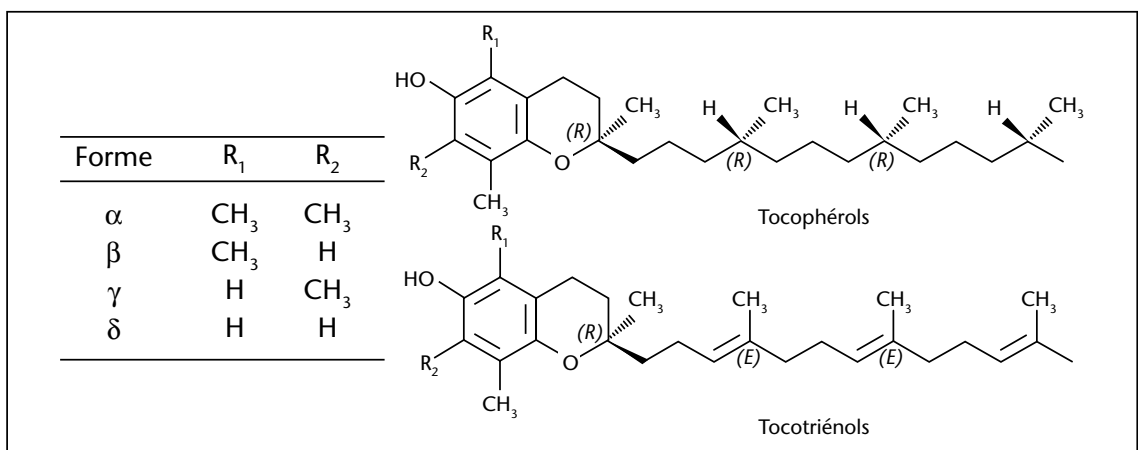

Figure 2. Structure des tocochromanols. Tous les isomères naturels des tocophérols ont la même configuration stéréochimique, la forme RRR. molécule uniquement. En revanche, tous les tocochromanols ont une activité antioxydante (Traber, 2007).

\section{Rôle dans la plante}

Les tocophérols sont des composés membranaires essentiels synthétisés dans la membrane interne des plastes (DellaPenna et Pogson, 2006). L'a-tocophérol est spécifiquement présent dans les tissus photosynthétiquement actifs, il les protège en réduisant les oxygènes actifs et les radicaux péroxydes produits par les photosystèmes et aide ainsi à la tolérance au stress (Falk et Munne-Bosch, 2010 ; Lichtenthaler, 2007). Son rôle est cependant plus large et incomplètement élucidé, il a été mis en évidence dans la régulation de l'assimilation carbonée sous stress, en particulier sous les basses températures (Maeda et al., 2008), et dans la signalisation de la mort cellulaire (Li et al., 2008).

La production des autres tocochromanols a surtout lieu lors de la différenciation des oléosomes (Fisk et al., 2006). Le $\gamma$-tocophérol semble particulièrement impliqué dans la tolérance au stress osmotique et à la dessiccation, ce qui explique sa grande importance dans la plupart des fruits et des graines. De même, les tocotriénols ne sont présents que dans les graines, ils pourraient avoir un rôle différent des tocophérols. Ces deux catégories de tocochromanols ne sont pas localisées au même endroit dans l'embryon et pourraient le protéger contre l'oxydation des lipides de réserve et maintenir sa viabilité lors de la dessication (Falk et Munne-Bosch, 2010).

\section{Variation de la teneur dans I'huile}

La teneur et la composition en tocophérols dans les huiles varient selon les espèces végétales et au sein d'une même espèce selon les génotypes (tableau 1). Parmi les oléagineux, le tournesol se situe entre le colza et le soja avec une teneur totale en tocophérols de 546 à $1872 \mathrm{mg} / \mathrm{kg}$ d'huile selon les génotypes (Demurin et al., 1996 ; Velasco et al., 2002 ; Ayerdi-Gotor et al., 2006). La cinétique d'accumulation dans la graine montre un maximum $d^{\prime}$ activité entre trois et quatre semaines après la floraison, ce qui coïncide avec la cinétique $d^{\prime}$ accumulation des acides gras (Ayerdi-Gotor et al., 2006). Le tournesol est le seul oléagineux dont les tocochromanols sont constitués essentiellement $d^{\prime} \alpha$-tocophérol. Ce qui en fait une huile au profil particulièrement intéressant pour I'alimentation humaine et animale, de par sa très grande activité vitaminique.

Quelles que soient les espèces, on trouve une part significative de variation due à des effets environnementaux. Ainsi, l'effet du lieu de culture s'est montré significatif sur le colza (Marwede et al., 2004), sur l'avoine et l'orge (Peterson et Qureshi, 1993), sur le soja (Dolde 


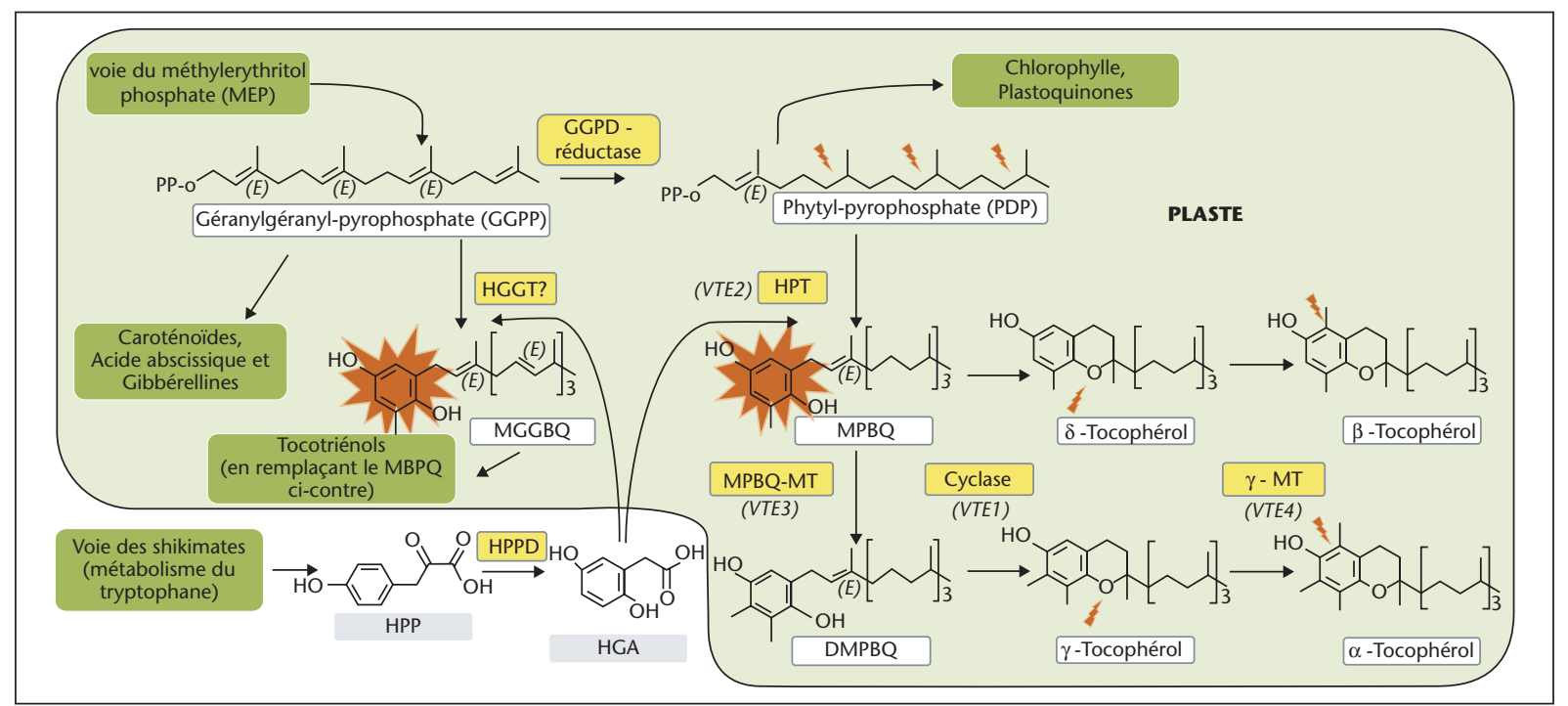

Figure 3. Biosynthèse de tocophérols. Enzymes : GGPD : géranylgéranyl pyrophosphate réductase; HPT : homogentisate phytyltransférase; HGGT : homogentisate géranylgéranyl transférase (cette fonction est peut-être assurée par HPT) ; MPBQ-MT : methyl-phytyl-benzoquinone-méthyltransférase; $\gamma$-MT : $\gamma$-tocophérol méthyltransférase; HPPD : HPP dioxygénase. Les sigles VTE (vitamine E) sont aussi utilisés pour les différents points clés de la biosynthèse. Métabolites: MGGBQ : 2-méthyl-6-géranylgéranyl1,4-benzoquinone; MPBQ : 2-méthyl-6-phytyl-1,4-benzoquinone; DMPBQ : 2,3-diméthyl-6-phytyl-1,4-benzoquinone; HPP: p-hydroxyphénylpyruvate; HGA: acide homogentisique.

et al., 1999) et sur le tournesol (Velasco et al., 2002). Une augmentation de la température entraîne une diminution des tocophérols libres, chez le soja (Dolde et al., 1999) ou chez le tournesol (Izquierdo et al., 2007). Mais d'autres auteurs montrent plutôt une augmentation en cas de stress, qu'il soit thermique ou hydrique, cette variation ne touchant en fait que l' $\alpha$-tocophérol et cet effet serait dépendant de la variété (Britz et Kremer, 2002). La teneur en tocophérols diminue avec un stockage prolongé des graines lié à une réduction de leur viabilité (Tammela et al., 2005 ; Zacheo et al., 2000 ; Lampart-Szczapa et al., 2003). La teneur en tocophérols diminue d'autant plus rapidement que la graine est décortiquée ou endommagée (Zacheo et al., 2000; Wagner et al., 2003).

La variabilité génétique des teneurs et des compositions en tocophérols a été démontrée chez de nombreuses espèces cultivées : colza, soja, avoine, blé, maïs, riz (Dolde et al., 1999 ; Kurilich et al., 1999; Goffman et Becker, 2002 ; Velasco et al., 2002 ; Bergman et Xu, 2003 ; Hampshire, 1993). Une étude multilocale (13 départements en France) et pluriannuelle (de 2002 à 2004) sur quatre génotypes (Aurasol $^{\circledR}$, All-star RM, Melody et Prodisol) a montré un effet génotypique significatif : Prodisol, avec une teneur moyenne en tocophérols totaux de $804,8 \mathrm{mg} / \mathrm{kg}$ d'huile est significativement plus riche que Melody $(664,8 \mathrm{mg} / \mathrm{kg})$. Les fortes chaleurs de l'année 2003 ont par ailleurs entraîné une diminution significa- tive de la teneur en tocophérols totaux chez les quatre variétés (Ayerdi-Gotor, 2008). Une étude par croisements de type top cross de sept lignées mâles croisées par sept lignées femelles a montré, après culture des 47 hybrides F1 sur deux années (2005 et 2006) sur six lieux en France, que la teneur en tocophérols était héritable. La décomposition de la variance indique la présence principalement de variance additive (forte aptitude générale à la combinaison) conduisant à une héritabilité au sens étroit plutôt élevée $\left(h^{2}=0,62\right)$, ce qui permet la mise en place de programme de sélection précoce (Ayerdi-Gotor et al., 2008a). Chez le brocoli et le maïs doux, la part de variation de la teneur en tocophérol due aux effets génotypiques représente plus de $50 \%$ de la variance phénotypique (Ibrahim et Juvik, 2009). Quelques QTL relativement forts $\left(\mathrm{R}^{2} \approx 10 \%\right)$ ont été mis en évidence pour les $\alpha$ - et les $\gamma$-tocophérols chez le soja (Li et al., 2010).

\section{Variation de profil}

De nombreux travaux publiés sur le tournesol sont orientés vers une modification du profil des tocophérols afin d'augmenter la stabilité de l'huile (le $\gamma$-tocophérol étant le plus antioxydant). De récentes études proposent des génotypes dont la teneur en $\beta$-, $\delta$ - ou $\gamma$-tocophérol est supérieure à celle de l' $\alpha$-tocophérol (Velasco et al., 2004a). L'accumulation des tocophérols serait sous l'influence de deux gènes (Tph1 et Tph2). Tph1 interviendrait sur la concentration en $\alpha$ - et en $\beta$ - tocophérol. Si l'on se réfère aux voies de synthèse, cette fonction concernerait probablement l'activité MPBQ méthyl transférase (figure 3 ). Le gène Tph2 contrôlerait le niveau $d^{\prime} \alpha$ - et de $\gamma$ - tocophérols, c'est-à-dire I'activité VTE3, tandis que Thp1 contrôlerait la méthylation du MBPQ, donc la balance entre les deux branches de la synthèse (VTE4) (Demurin et al., 2004). Ces deux locus seraient indépendants (Vera-Ruiz et al., 2006), car ils sont localisés dans des groupes de liaison différents. Des mutants avec des teneurs élevées en $\gamma$-tocophérol (85\%), en $\beta$-tocophérol (jusqu'à $77 \%$ ) ou en $\delta$-tocophérol (jusqu'à $73 \%$ ) ont été obtenus par combinaison des deux mutations (Velasco et al., 2004a ; Garcia-Moreno et al., 2006). La teneur en $\beta$-tocophérol peut être encore augmentée par une triple mutation : en fait, l'activité VTE4 semble codée par deux gènes (Hass et al., 2006; Tang et al., 2006).

L'augmentation de la teneur en tocophérols, et plus particulièrement de la forme $\alpha$-tocophérol, reste possible avec la surexpression des activités VTE2 et VTE4 qui permettent de diminuer la teneur des autres formes tocophérols (DellaPenna et Pogson, 2006). La teneur totale dans les graines chez arabidopis peut être multipliée par plus de dix (Collakova et DellaPenna, 2003), des résultats du même type ont été obtenus chez le soja en utilisant cette double mutation, combinée à une surexpression de la synthèse de la tête chromanol et de la GGPD réductase (figure 3). Cependant, plus de $90 \%$ des tocochomanols accumulés sont des tocotriénols (Karunanandaa et al., 2005). 
Tableau 1. Teneur ( $\mathrm{mg} / \mathrm{kg}$ d'huile) et composition (\%) en tocophérols dans les principales huiles végétales.

\begin{tabular}{|c|c|c|c|c|c|c|}
\hline & \multicolumn{4}{|c|}{ Tocophérols (\%) } & \multirow{2}{*}{$\begin{array}{l}\text { Teneur } \\
\text { totale }\end{array}$} & \multirow{2}{*}{ Source } \\
\hline & $\alpha$ & $\beta$ & $\gamma$ & $\delta$ & & \\
\hline Amande douce & 70 & 1 & 29 & I & & (www.foodscience.az.nz, 2007) \\
\hline \multirow[t]{3}{*}{ Arachide } & 56 & 1 & 42 & 1 & 215 & (Verleyen, 2002) \\
\hline & 40 & l & 46 & 14 & 332 & (De Greyt et al., 1998) \\
\hline & 36 & l & 58 & 6 & 396 & (Bramley et al., 2000) \\
\hline Argan & 10 & 1 & 75 & 14 & 365 & (Khallouki et al., 2005) \\
\hline \multirow[t]{2}{*}{ Carthame } & 83 & l & 17 & l & 600 & (Bramley et al., 2000) \\
\hline & 92 & 2 & 5 & 1 & 413 & (Lampi et al., 2002) \\
\hline Chanvre & 7 & 1 & 5 & 87 & n.s. & (Kriese et al., 2004) \\
\hline \multirow[t]{3}{*}{ Colza } & 28 & l & 71 & 2 & 690 & (Grusak et DellaPenna, 1999) \\
\hline & 35 & 1 & 63 & 2 & n.s. & (Bramley et al., 2000) \\
\hline & 26 & l & 71 & 2 & 254 & (Verleyen, 2002) \\
\hline \multirow[t]{2}{*}{ Germe de blé } & 52 & 28 & 10 & 10 & 739 & (Bramley et al., 2000) \\
\hline & 64 & 13 & 23 & l & 2571 & (Lampi et al., 2002) \\
\hline \multirow[t]{3}{*}{ Maïs } & 14 & 6 & 77 & 3 & n.s. & (Bramley et al., 2000) \\
\hline & 22 & 2 & 73 & 3 & 782 & (Warner et Mounts, 1990) \\
\hline & 33 & l & 63 & 3 & 540 & (Sanchez-Perez et al., 2000) \\
\hline \multirow[t]{2}{*}{ Noisette } & 93 & $>2$ & 3 & $<1$ & 770 & (Crews et al., 2005a) \\
\hline & 99 & l & 1 & l & n.s. & (Bramley et al., 2000) \\
\hline Noix & 3 & l & 93 & 4 & n.s. & (Crews et al., 2005b) \\
\hline Noix coco & 45 & l & 55 & l & 400 & (Bramley et al., 2000) \\
\hline \multirow[t]{3}{*}{ Olive } & 93 & l & 7 & l & 11 & (Sanchez-Perez et al., 2000) \\
\hline & 94 & I & 6 & l & 140 & (Bramley et al., 2000) \\
\hline & 41 & l & 58 & 1 & 126 & (Verleyen, 2002) \\
\hline Pépin de courge & 11 & l & 72 & 17 & 108 & (Stevenson et al., 2007) \\
\hline \multirow[t]{3}{*}{ Soja } & 7 & 1 & 69 & 23 & 678 & (Bramley et al., 2000) \\
\hline & 12 & 1 & 61 & 26 & 1153 & (Warner et Mounts, 1990) \\
\hline & 12 & l & 68 & 20 & 1000 & (Verleyen, 2002) \\
\hline Sésame & 32 & l & 68 & l & 1173 & (Verleyen, 2002) \\
\hline \multirow[t]{5}{*}{ Tournesol } & 96 & 2 & 2 & l & 447 & (Grusak et DellaPenna, 1999) \\
\hline & 90 & l & 9 & 1 & n.s & (Bramley et al., 2000) \\
\hline & 92,4 & 1,5 & 4,4 & 1,5 & 546 & (Warner et Mounts, 1990) \\
\hline & 88 & 7 & 5 & l & 660 & (Sanchez-Perez et al., 2000) \\
\hline & $88-96$ & $3-9$ & $1-4$ & l & 709 & (Velasco et al., 2002) \\
\hline
\end{tabular}

n.s. : non spécifié.

\section{Phytostérols}

Les stérols des plantes ou phytostérols sont des alcools stéroïdes, membres de la famille des terpènes. Les phytostérols sont constitués d'un assemblage tétracyclique cyclopentaphénanthrénique (A, B, C, D) comprenant un groupement hydroxyle en position 3 du cycle A et une chaîne latérale méthylée ou non en C24. Les phytostérols ont une structure chimique similaire au cholestérol (figure 4).

Les principaux phytostérols des plantes sont le $\beta$-sitostérol, le stigmastérol et le campestérol (figure 4). Les champignons produisent presqu'exclusivement un composé qui leur est spécifique : l'ergostérol. Ces composés sont les équivalents du cholestérol des vertébrés. Chez le tournesol, le $\beta$-sitostérol, largement majoritaire, représente environ $60 \%$ des phytostérols totaux (Phillips et al., 2002). Les stérols se trouvent aussi sous forme conjuguée. Le radical hydroxyl présent en C3 peut être la cible de plusieurs transformations: une estérification, souvent par l'acide oléique ou palmitique, donnera un stéryl ester (SE); une glycoslysation produira un stéryl glucoside (SG). En général, le sucre est un glucose, et il peut aussi être acylé en $C 6$ ' pour donner un acyl SG (ASG).

Dans I'huile, la forme libre est la plus fréquemment rencontrée. Elle contient environ $60 \%$ des stérols sous forme libre et le reste est sous forme estérifiée (Phillips et al., 2002). Les phytostérols sont appelés stanols lorsqu'ils sont hydrogénés, ils sont à l'état de traces dans les plantes, les oléagineux et les huiles végétales et en quantités plus importantes lors de la transformation d'un produit pour un usage commercial (Moreau et al., 2002).

\section{Biosynthèse}

Les phytostérols sont synthétisés au niveau du réticulum endoplasmique via la voie du mévalonate, puis ils sont transportés vers la membrane plasmique via l'appareil de Golgi. Le mécanisme de ce transport vers les membranes n'est pas encore élucidé chez les plantes, il implique probablement des transporteurs protéiques du même type que les oxysterolbinding-protein connus chez les animaux et les champignons (Boutte et Grebe, 2009).

Le mévalonate permet de produire le farnesyl diphosphate qui est ensuite condensé en une molécule de squalène. Puis, grâce à une époxidase (squalène epoxydase [SQE]), le squalène est transformé en 2,3 oxydosqualène (figure 5). La méthylation du cycloarténol sur le carbone 24, catalysée par la SMT1, est spécifique des végétaux et marque l'entrée dans la voie des phytostérols. Par l'intermédiaire de l'obtusifoliol, le 24-métylène lophénol est produit. S'il est méthylé une seconde fois en C24 par un 


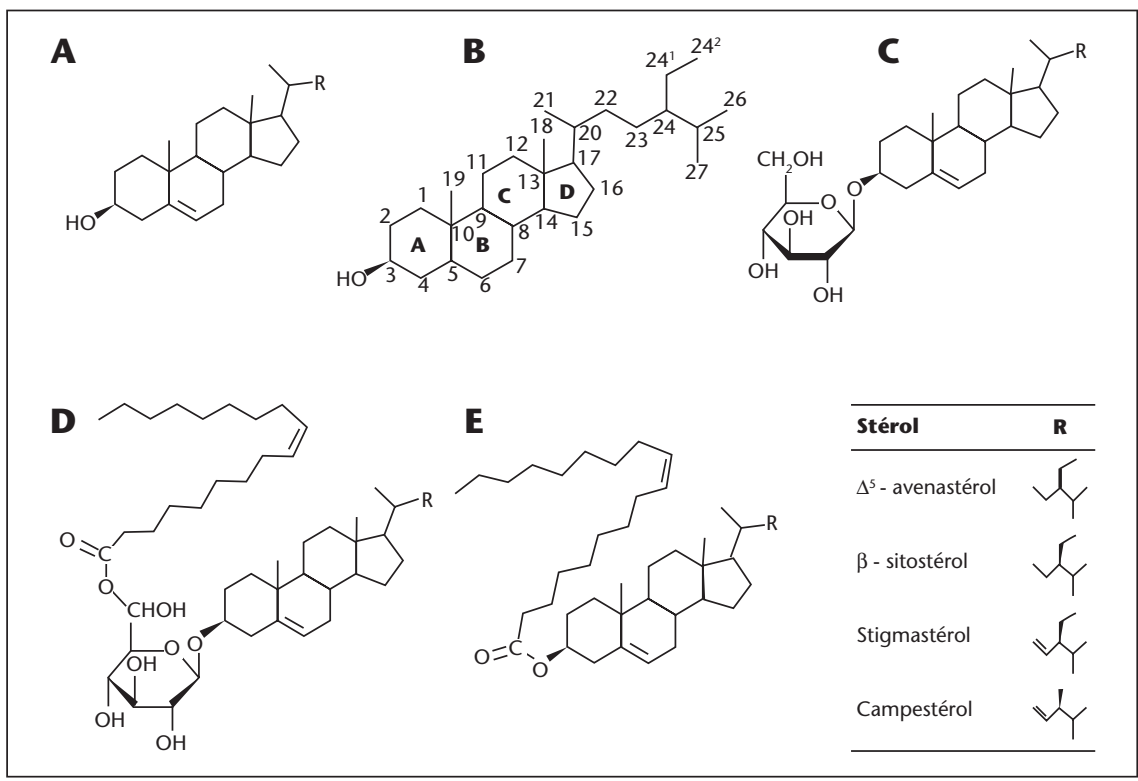

Figure 4. Structure chimique des phytostérols principaux de l'huile de tournesol. A) structure générale d'un stérol libre; B) numérotation des carbones (contrairement au cholestérol, les phytostérols portent sur le carbone 24 un groupement éthyl ( $\beta$-sitostérol ou stigmastérol) ou méthyl (campestérol) ; C) stéryl glucoside (SG); D) acyl stéryl glucoside (ASG) et ; E) stéryl ester ou (SE). L'acide gras pris en exemple ici est l'acide oléique, et les conjugués représentés sont un oléoylstérol (en E) et un oléoyl glycosylstérol (en D).

stérol méthylase spécifique (SMT2), il donnera les éthyl stérols dont font partie le $\beta$-sitostérol et le stigmastérol, sinon, les mêmes enzymes produiront les méthyl stérols, dont le campestérol, point d'entrée dans le métabolisme des brassinostéroïdes (Piironen et al., 2000a; Schaller, 2004 ; Schaller, 2003 ; Boutte et Grebe, 2009). L'un des facteurs limitants de l'accumulation des phytostérols est la synthèse du mévalonate: celui-ci dépend de l'activité 3hydroxy-3-méthylglutaryl coenzyme $\mathrm{A}$ réductase 1 (HMGR1), et lorsque cette enzyme est sur activée, l'accumulation des phytostérols peut être multipliée par deux ou trois (Harker et al., 2003 ; Schaller, 2003 ; Hey et al., 2006).

\section{Intérêt pour la santé}

C'est en raison de leur pouvoir hypocholestérolémiant que les stérols d'origine végétale ont suscité le plus d'intérêt. Grâce à leurs propriétés amphiphiles, ils inhibent l'absorption intestinale du cholestérol en le remplaçant dans les micelles de sels biliaires (Trautwein et al., 2003 ; Brufau et al., 2008). Les phytostérols sont aussi étudiés pour leur action anticancéreuse (Bradford et Awad, 2007), immunomodulatrice et anti-inflammatoire (Bouic et Lamprecht, 1999). Ils sont aujourd'hui largement utilisés en industrie agroalimentaire pour la fabrication d'aliments fonctionnels. En raison de leurs caractères amphiphiles, les phytostérols possèdent également un pouvoir émulsifiant et pénétrant. Cette propriété est cellulaire, en tant que médiateurs de l'interaction entre les protéines et les lipides membranaires (Schaller, 2003).

Les stérols des champignons et des animaux sont impliqués, au côté des sphingolipides et des protéines spécifiques, dans l'organisation de microdomaines membranaires appelés rafts (Eggeling et al., 2009). Ces microdomaines sont moins bien caractérisés chez les plantes, mais leur existence ou des systèmes équivalents sont actuellement étudiés (Zappel et Panstruga, 2008). Par ce biais, on pourrait mieux comprendre la forte implication des phytostérols dans le transport de l'auxine, la polarisation des cellules, l'endocytose et la communication intercellulaire (Boutte et Grebe, 2009). Les phytostérols jouent également un rôle déterminant dans la division et la différenciation cellulaire et plus particulièrement dans la régulation du développement embryonnaire ainsi que dans la fertilité en facilitant la germination du tube pollinique (Clouse, 2000). Les variations de teneurs en phytostérols pourraient être corrélées avec l'adaptation des plantes aux variations de température (Palta et al., 1993).

Les stérols se trouvent en faibles quantités dans le réticulum endoplasmique, le tonoplaste, les membranes mitochondriales et dans les chloroplastes. Ils ne sont pas présents dans les membranes des thylacoïdes (Hartmann, 1998). Les SE, présents en grande quantité dans les organes de réserve, sont impliqués dans le stockage des stérols et la régulation de leur teneur dans les membranes. La phospholipid stérol acyl tranférase responsable de cette estérification (PSAT) est fortement stimulée par la présence de stérols libres (Banas et al., 2005). Le rôle des SG est probablement plus complexe. La fonction de ces glycoconjugués est encore mal connue. Ils pourraient avoir un rôle spécifique au niveau membranaire (Grille et al., 2010). Par exemple, le sitostérol SG serait l'initiateur de la synthèse de la cellulose chez le coton (Peng et al., 2002). On sait peu de choses sur leur rôle dans les graines. Récemment, on a montré que la fraction de stérols estérifiés diminuait durant la maturation de la graine pour s'établir à moins de $20 \%$ à 90 jours après floraison (Zlatanov et al., 2009).

\section{Variations de la teneur dans I'huile}

Comme pour les tocophérols, la teneur et la composition des phytostérols varient en fonction de l'espèce végétale : soja, colza, tournesol, avoine et selon les variétés (tableau 2). La majorité des huiles végétales contiennent de 1 à $5 \mathrm{~g}$ de stérols/kg d'huile. L'huile de tournesol est particulièrement riche puisque les extraits par pression à froid peuvent présenter jusqu'à 0,5 ou $1 \%$ de phytostérols totaux dans leur huile (Piironen et al., 2000b). L'huile 


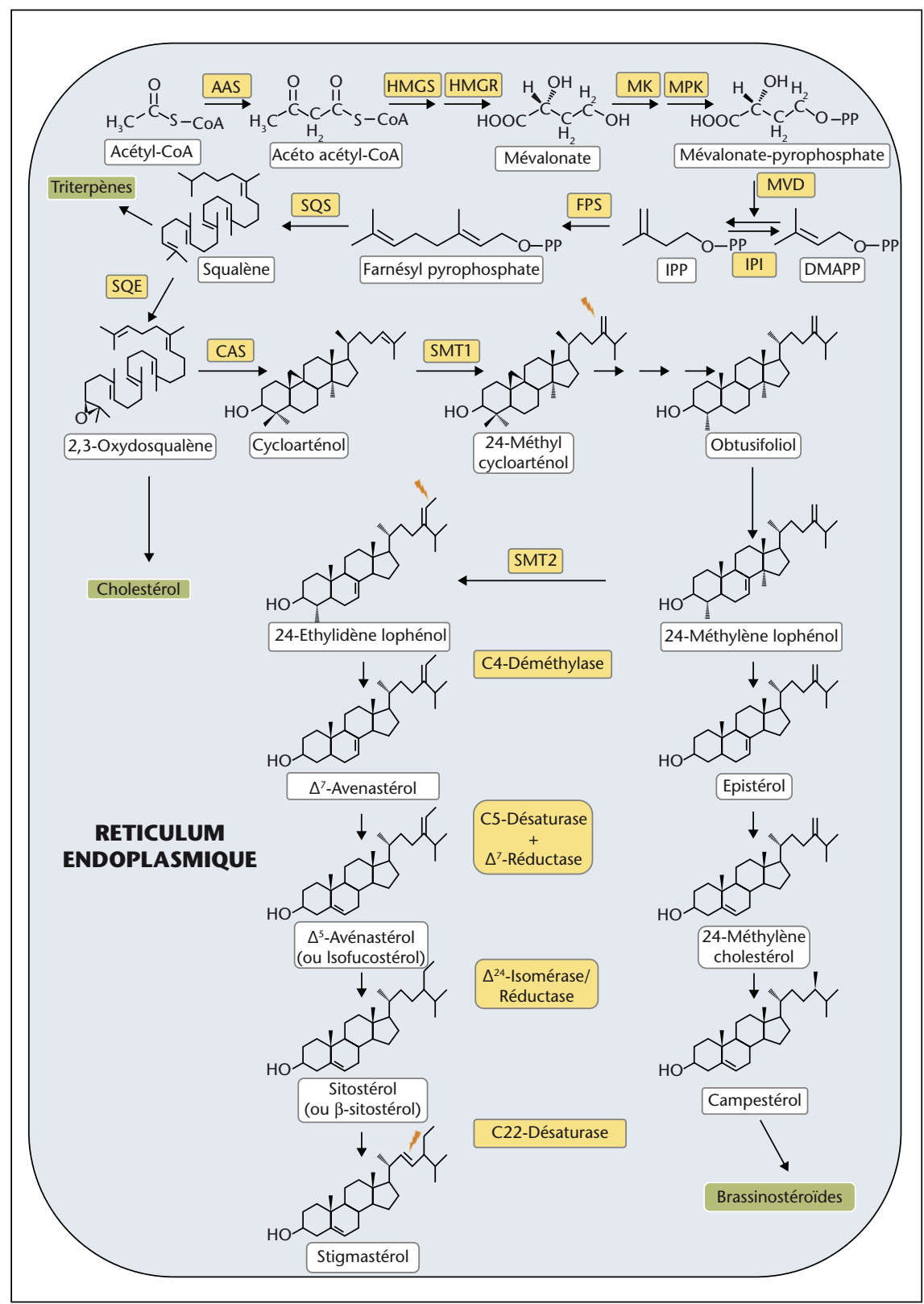

Figure 5. Synthèse des phytostérols du tournesol. Enzymes: AAS: acyl acétyl-CoA synthase; HMGS: 3-hydroxy-3-methylglutaryl-COA synthase; HMGR : 3-hydroxy-3-méthylglutaryl-CoA réductase; MK: mévalonate kinase; MPK : phosphomévalonate kinase; MVD: mévalonate diphosphate décarboxylase-IPI : IPP isomérase; FPS : farnésyl diphosphate synthase; SQS : squalène synthase; SQE : squalène époxidase; CAS : cycloartenol synthase; SMT1 : stérol méthyltransférase 1; SMT2 : stérol méthyltransférase 2. Métabolites: IPP : isopentényl diphosphate; DMAPP : dimethylallyl diphosphate. Les flèches rouges indiquent les modifications apportées par les réactions enzymatiques. Le cholestérol n'est pas synthétisé par le tournesol, mais on le trouve à l'état de traces chez certains végétaux. Dans ce cas, il est synthétisé à partir du cycloarténol alors qu'il est issu du lanostérol chez les animaux.

de tournesol contient majoritairement du $\beta$-sitostérol devant le campestérol et le stigmastérol. Contrairement au colza, elle ne contient pratiquement pas de squalène qui participe à la synthèse des graisses et à la formation du cholestérol, ce qui lui confère des atouts nutritionnels.
(Maatta et al., 1999). D'après Vlahakis et Hazebroek (2000), la teneur totale en phytostérols augmente avec la température durant la maturation de la graine sur du soja. La teneur en phytostérols totaux apparaît significativement augmentée par les fortes températures chez certains hybrides de tournesol (Ayerdi-Gotor et al., 2008b). Au contraire, sur du seigle, elle diminue si les températures sont élevées (Zangenberg et al., 2004). Pendant la maturation des akènes, la cinétique d'accumulation varie selon les différentes formes de phytostérols. Pour le $\Delta^{7}$-avénastérol, l'accumulation se réalise pendant toute la phase de maturation, tandis que pour le campestérol et le stigmastérol, le maximum est atteint avant le $26^{\mathrm{e}}$ jour après floraison et reste stable ou diminue légèrement, pendant la maturation de l'akène (Ayerdi-Gotor et al., 2008b). Une étude biannuelle portant sur la comparaison de trois hybrides de tournesol (Santiago, Proléic 204 et Ichraqles) montre que la date de semis influe sur le remplissage de l'akène, mais également qu'un apport en eau entraîne une diminution de la teneur en phytostérols (Roche et al., 2006).

L'étude de la cinétique d'accumulation des phytostérols en condition normale de culture sur quatre variétés hybrides, en 2002 et 2003, montre que relativement à la matière sèche de la graine, la teneur finale de I'huile en phytostérols totaux est atteinte dès la troisième semaine après floraison, ce qui correspond au maximum d'accumulation des acides gras. Une étude récente a montré que $25 \%$ des phytostérols semblent provenir de la coque (Roche et al., 2010). Chez le colza, l'étude d'une population d'haploïdes doublés a mis en évidence trois QTL expliquant $60 \%$ de la variance de la teneur totale en phytostérols. Le profil étant peu affecté par ces QTL, ils pourraient plutôt concerner les activités HMGR et SMT1 (figure 5). La corrélation inverse entre les teneurs en acide érucique et en phytostérols pourrait indiquer une compétition entre les FAE et la voie du mévalonate pour l'acétyl-CoA dont la teneur serait limitante dans le réticulum endoplasmique (Amar et al., 2008). II existe des différences entre les hybrides pour la teneur en phytostérols chez le tournesol, mais l'étude d'un top cross entre sept lignées mâles et sept lignées femelles n'a pas montré de forts effets additifs (Ayerdi-Gotor, 2008).

\section{Variation des profils}

Peu d'études traitent des modifications de composition des phytostérols sur la culture du tournesol. La composition en phytostérols varie significativement, avec une augmentation du pourcentage en campestérol et une faible diminution des teneurs en stigmastérol et en $\beta$-sitostérol, lorsque la température augmente, 
Tableau 2. Teneur et composition en phytostérols ( $\mathrm{g} / 100 \mathrm{~g}$ d'huile) dans les principales huiles végétales.

\begin{tabular}{|c|c|c|c|c|c|c|}
\hline & \multicolumn{4}{|c|}{ Phytostérols (mg/100 g d'huile) } & \multirow[b]{2}{*}{ Total stérols } & \multirow[b]{2}{*}{ Source } \\
\hline & Campestérol & Stigmastérol & $\beta$-sitostérol & Autres & & \\
\hline Amande douce & 5 & 3 & 122 & 13 & 143 & Instituto de la grasa \\
\hline \multirow[t]{2}{*}{ Arachide } & 38 & 22 & 169 & 0 & 229 & (Verleyen, 2002) \\
\hline & 15 & 4 & 68 & 84 & 171 & (Phillips et al., 2002) \\
\hline \multirow[t]{2}{*}{ Carthame } & 49 & 40 & 231 & 124 & 444 & Instituto de la grasa \\
\hline & 10 & 34 & 2 & 158 & 204 & (Phillips et al., 2002) \\
\hline \multirow[t]{3}{*}{ Colza } & 136 & - & 224 & 308 & 668 & (Phillips et al., 2002) \\
\hline & 309 & - & 404 & 0 & 713 & (Verleyen, 2002) \\
\hline & 104 & 3 & 183 & 3 & 293 & (Lechner et al., 1999) \\
\hline \multirow[t]{3}{*}{ Germe de blé } & 122 & Traces & 303 & 0 & 425 & (Verleyen, 2002) \\
\hline & 102 & 4 & 304 & 0 & 410 & (Ostlund et al., 2003) \\
\hline & 37 & - & 63 & 0 & $\%$ & (Ballesteros et al., 1995) \\
\hline \multirow[t]{2}{*}{ Graine de coton } & 32 & 4 & 357 & 15 & 408 & (Verleyen, 2002) \\
\hline & 9 & 1 & 75 & 215 & 300 & (Phillips et al., 2002) \\
\hline \multirow[t]{3}{*}{ Maïs } & 24 & 36 & 37 & 0 & $\%$ & (Ballesteros et al., 1995) \\
\hline & 200 & 68 & 646 & 0 & 914 & (Verleyen, 2002) \\
\hline & 71 & 34 & 291 & 377 & 773 & (Phillips et al., 2002) \\
\hline \multirow[t]{3}{*}{ Noix } & 7 & 1 & 140 & 18 & 166 & (Crews et al., 2005b) \\
\hline & 6 & Traces & 87 & 15 & 108 & Instituto de la grasa \\
\hline & 8 & 1 & 142 & 13 & 164 & (Amaral, et al. 2003) \\
\hline \multirow[t]{3}{*}{ Noix de coco } & 3 & 3 & 15 & 52 & 73 & (Phillips et al., 2002) \\
\hline & $6-11,2$ & $11,4-15,6$ & $32,6-50,7$ & - & $40-120$ & (Codina.net, 2007) \\
\hline & 8 & 12 & 48 & 1 & 69 & (Verleyen, 2002) \\
\hline \multirow[t]{3}{*}{ Olive } & 2 & 1 & 52 & 95 & 150 & (Phillips et al., 2002) \\
\hline & 5 & - & 127 & 61 & 193 & (Verleyen, 2002) \\
\hline & 2 & - & 98 & 0 & $\%$ & (Ballesteros et al., 1995) \\
\hline \multirow[t]{2}{*}{ Palme } & 14 & 10 & 43 & 0 & 67 & (Verleyen, 2002) \\
\hline & 13 & 8 & 34 & 12 & 67 & Instituto de la grasa \\
\hline \multirow[t]{2}{*}{ Sésame } & 38 & 9 & 114 & 345 & 506 & (Phillips et al., 2002) \\
\hline & 33 & 22 & 113 & 72 & 240 & (Dachtler et al., 2003) \\
\hline \multirow[t]{3}{*}{ Soja } & 6 & 4 & 40,3 & 246,7 & 297 & (Phillips et al., 2002) \\
\hline & 91 & 82 & 175 & 12 & 360 & (Lechner et al., 1999) \\
\hline & 32 & 35 & 210 & 73 & 350 & (Sánchez-Muniz et al., 2004) \\
\hline \multirow[t]{3}{*}{ Tournesol } & 34 & 36 & 187 & 93 & 350 & (Sánchez-Muniz et al., 2004) \\
\hline & 12 & 3 & 100 & 237 & 352 & (Phillips et al., 2002) \\
\hline & 31 & 20 & 186 & 113 & 350 & (Lechner et al., 1999) \\
\hline
\end{tabular}

n.s. : non spécifié. 
ce qui pourrait indiquer une différence de comportement de la SMT2 (Ayerdi-Gotor et al., 2008b). Le rapport sitostérol/campestérol semble influencé aussi par l'apport en azote chez le colza (Gul et al., 2007). D'une manière générale, la manipulation de la balance entre les méthyl et les éthyl stérols est délicate, car leur équilibre peut affecter fortement le phénotype de la plante, en modifiant la synthèse des brassinostéroïdes ou par l'influence directe du stigmastérol sur le développement de la plante (Boutte et Grebe, 2009). Une forte augmentation de la synthèse des phytostérols s'accompagne en général d'une augmentation de la teneur de la graine en SEs.

\section{Extraction et quantification de I'huile et analyse}

Les procédés industriels permettent $d$ 'extraire quasiment toute l'huile, mais ces différentes opérations d'extraction au solvant suivies du raffinage altèrent la composition de I'huile en diminuant les composés bénéfiques tels que les tocophérols et en faisant apparaître des acides gras trans (Brevedan et al., 2000). À l'échelle du laboratoire, la détermination de la composition des akènes commence par une extraction de I'huile. Deux méthodes d'extraction à chaud sont utilisées. La méthode normalisée du Soxhlet NF ENISO 659 (1998), basée sur une extraction de I'huile à l'hexane, nécessite plusieurs extractions pour extraire la totalité de l'huile. Cette méthode s'avère longue, fastidieuse et consommatrice de solvant. La seconde méthode est une extraction automatique de I'huile ASE (accelerated solvent extractor). Elle repose sur le même principe que la précédente, mais elle fonctionne à des températures et des pressions élevées afin d'accroître l'efficacité de l'extraction. Cette technique est rapide (30 minutes par échantillon) et très économe en solvant. La comparaison des différentes techniques d'extraction ainsi que les paramètres déterminant les conditions d'extraction et le nombre de cycles ont été définis par Matthaus et Bruhl (1999).

Après extraction de l'huile, les teneurs et les compositions des tocophérols peuvent être déterminées par chromatographie liquide haute performance (HPLC) selon la norme ISO 9936 (EC, 1997), tandis que les teneurs et compositions des acides gras et des phytostérols, après dérivatisation, sont déterminées par chromatographie en phase gazeuse (CPG) NF EN ISO 5508 (EC, 1995) et ISO 12228 (EC, 1999). Ces méthodes de référence sont plutôt longues et coûteuses, elles utilisent des produits chimiques dangereux (hexane) et requièrent du personnel qualifié. Elles sont donc difficiles à concilier avec les besoins des programmes de sélection qui nécessitent un outil analytique rapide, fiable et facile à mettre en œuvre pour sélectionner des lignées et des hybrides en grande quantité.

La spectrométrie proche infrarouge (SPIR) peut répondre en partie à cette demande. Elle est utilisée pour déterminer différents paramètres sur une grande variété de matrices de graines ou d'huiles végétales à partir de la discrimination de certaines bandes d'absorption (Hourant et al., 2000). II est ainsi possible d'estimer les taux d'humidité, la teneur en huile, les taux de protéines et de composition en acides gras par SPIR sur des graines de sésame (Sato et al., 2004 ; Sato et al., 2003) ; le profil d'acides gras sur graines entières de colza (Sato et al., 1998) ou sur des olives entières (Leon et al., 2003). Malgré la lourdeur de la phase d'étalonnage, I'analyse SPIR permet des analyses simultanées sur plusieurs composés, avec une grande rapidité, une faible quantité de produit et un coût analytique faible. Cette technique peut être utilisée en laboratoire ou comme système embarqué. L'importance du développement $\mathrm{d}$ 'hybrides de tournesol à haute teneur en acide oléique a impulsé, ces dernières années, de nombreuses études pour évaluer la capacité de la SPIR à prédire la composition en acides gras.

Les mesures sur tournesol posent cependant un problème particulier en raison de l'interférence de la coque noire de l'akène avec les infrarouges. De nombreux travaux se sont penchés sur cette question : akène entier non décortiqué, akène entier décortiqué, akènes broyés ou huile (Sato et al., 1995 ; Perez-Vich et al., 1998 ; Velasco et al., 1999 ; Velasco et al., 2004b ; Moschner et Biskupek-Korell, 2006 ; Ayerdi-Gotor et al., 2008c). Les résultats montrent que I'outil SPIR permet de prédire avec un coefficient de détermination supérieur à $98 \%$ les teneurs en acide oléique et en acide linoléique pour toutes les matrices excepté sur la graine intacte. La prédiction des autres acides gras tels que l'acide palmitique et l'acide stéarique est obtenue avec une précision moindre $\left(\mathrm{R}^{2}=80 \%\right)$, car la gamme de variabilité des teneurs est plus étroite pour ces deux composés. Un meilleur coefficient de détermination sur une graine entière $\left(R^{2}=88 \%\right)$ a été obtenu par la création d'hybrides mutants enrichis en acide stéarique (Velasco et al., 2004a). La précision des équations de calibration dépend de la matrice de l'échantillon et des méthodes de référence. Les travaux de Perez-Vich et al. (1998), sur l'évaluation du profil d'acides gras, ont montré une diminution des valeurs de prédiction en fonction de la matrice utilisée (huile, graines entières ou broyées de tournesol) ; la meilleure prédiction étant celle réalisée sur des graines broyées. Ces travaux confir- ment l'importance de la nature de la matrice. Cependant, dans le cas du tournesol, la détermination sur une matrice d'akènes broyés ne répond pas complètement aux besoins des programmes de sélection du tournesol (un akène broyé ne peut plus être utilisé dans un programme de croisement). C'est pourquoi des équations de prédiction des teneurs en acides gras sur akène isolé entier décortiqué ont été développées (Ayerdi-Gotor et al., 2008). Les validations croisées ont montré une bonne capacité de prédiction, avec un avantage logique pour les acides gras les plus abondants (acide linoléique: $\mathrm{R}^{2}=0,970$, acide oléique : $R^{2}=0,969$; acide palmitique : $R^{2}=0,782$ et acide stéarique : $R^{2}=0,329$ ).

$L^{\prime}$ 'analyse des composés mineurs par SPIR est un sujet moins exploré dans la littérature. Pour l'analyse des tocophérols, des travaux sur la luzerne (Gonzalez-Martin et al., 2006) et sur des huiles végétales (Szlyk et al., 2005) montrent des coefficients de détermination très élevés $\left(R^{2}=0,99\right)$. L'analyse de la partie stérolique dans l'huile d'olive a été déterminée par spectrométrie de Raman à transformée de Fourier et montre que certaines bandes des composants ( $\beta$-carotène, lutéine) peuvent être facilement identifiées (Baeten et al., 2001). Les travaux de Calmon et al. (2009) montrent que l'on est très probablement à la limite actuelle de la capacité de la spectrométrie proche infrarouge pour doser sans extraction les constituants mineurs de l'akène de tournesol. Les validations croisées ont montré que les tocophérols totaux exprimés en $\mathrm{mg} / \mathrm{kg} \mathrm{d}^{\prime}$ huile $\left(R^{2}=0,60\right)$ et les phystostérols totaux exprimés en $\mathrm{mg} / 100 \mathrm{~g}$ de matière sèche $\left(R^{2}=0,61\right)$ n'étaient pas encore « mesurables » avec une grande précision. Les tocophérols et les phytostérols ont une teneur inférieure à $3 \%$ de la matière sèche, et il est difficile qu'ils soient prédits en toute sécurité. Cependant, la spectroscopie proche infrarouge donne la possibilité d'obtenir un classement par groupe des teneurs en tocophérols et en phytostérols utilisables en sélection (Ayerdi-Gotor, 2008). L'amélioration des équations de prédiction peut être envisagée en améliorant les résultats analytiques concernant les phytostérols en employant la spectrométrie de masse pour caractériser les phytostérols libres des stérols conjugués.

\section{Conclusion}

Ces dernières années ont vu des progrès spectaculaires dans la compréhension de la biosynthèse des acides gras et des composés mineurs de la graine de tournesol. La modification des profils et des teneurs est possible avec des combinaisons de mutations ciblées. La plus connue étant la mutation Ol dominante qui permet de 
produire en grande culture des tournesols à forte teneur en acide oléique. Le challenge étant maintenant d'obtenir des variétés à plus de $90 \%$. L'élucidation du déterminisme de cette mutation en montre aussi les faiblesses, les mécanismes de silencing sont souvent instables et répondent de manière très variable au fond génétique dans lequel ils sont introduits. Les composés mineurs peuvent aussi être modifiés, bien que dans certains cas, les mutations pourraient conduire à des anomalies des phénotypes. Une fois les gènes majeurs intégrés, I'interaction avec le fond génétique demande encore beaucoup de travail et les méthodes de mesures doivent permettre d'augmenter le débit analytique. L'approche chimiométrique (infrarouge, Raman, etc.) est à portée de main et sera l'outil complémentaire indispensable.

\section{RÉFÉRENCES}

Alpaslan M, Gunduz H. The effects of growing conditions on oil content, fatty acid composition and tocopherol content of some sunflower varieties produced in Turkey. Nahrung-Food 2000 ; 44 : 434-7.

Amar S, Ecke W, Becker HC, Mollers C. QTL for phytosterol and sinapate ester content in Brassica napus L. collocate with the two erucic acid genes. Theor Appl Genet 2008 ; 116 : 1051-61.

Amaral JS, Casal S, Pereira JA, Seabra RM, Oliveira B. Determination of sterol and fatty acid compositions, oxidative stability, and nutritional value of six walnut (L.) cultivars grown in Portugal. J Agric Food Chem $2003 ; 51: 7698-702$.

Ayerdi-Gotor A. Étude des variations des teneurs et de la variabilité des compositions en tocophérols et en phytostérols dans les akènes et l'huile de tournesol (Helianthus annuus L.). In: Institut National Polytechnique de Toulouse-Science des Agroressources, Université de Toulouse, France, 2008.

Ayerdi-Gotor A, Berger M, Labalette F, Centis S, Daydé J, Calmon A. Variabilité des teneurs et compositions des composés mineurs dans l'huile de tournesol au cours du développement du capitule. Partie l-tocophérols. OCL 2006; 13 : 206-12.

Ayerdi-Gotor A, Berger M, Labalette F, Centis S, Daydé J, Calmon A. Estimation of breeding potential for tocopherols and phytosterols in sunflower. In: 17th International Sunflower Conference, Cordoba, Spain: Secretaria General Technica. Servicio de Publicationes y Divulgationes. Junta de Andalucia 2008a ; 2 : 555-9.

Ayerdi-Gotor A, Berger M, Labalette F, et al. Variabilité des teneurs et compositions des composés mineurs dans I'huile de tournesol au cours du développement du capitule. OCL 2008b ; 15 : 400-6.
Ayerdi-Gotor A, Moreau P, Gaillard A, Calmon A. Caractérisation par infrarouge des teneurs en acides gras de la graine entière décortiquée de tournesol. In: 17th International Sunflower Conference, Cordoba, Spain: Secretaria General Technica. Servicio de Publicationes y Divulgationes. Junta de Andalucia 2008c ; $2: 757-61$.

Baeten V, Dardenne P, Aparicio R. Interpretation of fourier transform Raman spectra of the unsaponifiable matter in a selection of edible oils. / Agric Food Chem $2001 ; 49$ : 5098-107.

Ballesteros E, Gallego M, Valcarcel M. Simultaneous determination of sterols in edible oils by use of a continuous separation module coupled to a gaschromatograph. Anal Chim Act 1995 ; 308 : 253-60.

Banas A, Carlsson AS, Huang B, et al. Cellular sterol ester synthesis in plants is performed by an enzyme (phospholipid: sterol acyltransferase) different from the yeast and mammalian acyl-CoA: sterol acyltransferases. I Biol Chem 2005 ; 280 : 34626-34.

Baud S, Lepiniec L. Physiological and developmental regulation of seed oil production. Lipid Res 2010 ; $49: 235-49$

Bergman C], Xu Z. Genotype and environment effects on tocopherol, tocotrienol, and gammaoryzanol contents of Southern US rice. Cereal Chem $2003 ; 80: 446-9$.

Blouin JM, Chaves VE, Bortoli S, Forest C. Effet des acides gras sur l'inflammation et le cancer. $\mathrm{OCL}$ 2006 ; 13 : 331-6.

Bouic PJ, Lamprecht JH. Plant sterols and sterolins: a review of their immune-modulating properties. Altern Med Rev $1999 ; 4$ : 170-7.

Boutte $Y$, Grebe M. Cellular processes relying on sterol function in plants. Curr Op Plant Biol 2009; $12: 705-13$.

Bradford PG, Awad AB. Phytosterols as anticancer compounds. Mol Nutr Food Res 2007 ; 51 : 161-70.

Bramley PMI, Elmadfa I, Kafatos A, et al. Vitamin E. / Sci Food Agric 2000 ; 80 : 913-38.

Brevedan MIV, Carelli AA, Crapiste GH. Changes in composition and quality of sunflower oils during extraction and degumming. Grasas Y Aceite 2000 ; $51: 417-23$

Britz SJ, Kremer DF. Warm temperatures or drought during seed maturation increase free alphatocopherol in seeds of soybean (Glycine max L. Merr.). I Agric Food Chem 2002 ; 50 : 6058-63.

Brufau GM, Canela MA, Rafecas M. Phytosterols: physiologic and metabolic aspects related to cholesterollowering properties. Nutr Res $2008 ; 28$ : 217-25.

Calmon A, Ayerdi-Gotor A, Berger $M$, et al. Near infrared spectroscopy (NIRS) for improvement in sunflower breeding for fatty acids and minor components. In Word congress on oils and fats \& 28th ISF Congress. September 27-30, 2009. Sydney, Australia, 2009.

Cantisan S, Martinez-Force E, Alvarez-Ortega R, Garces R. Lipid characterization in vegetative tissues of high saturated fatty acid sunflower mutants. J Agric Food Chem 1999 ; 47 : 78-82.
Chenevert R, Courchesne G. Synthesis of (S)alpha-tocotrienol via an enzymatic desymmetrization of an achiral chroman derivative. Tetrahedr Let 2002 ; 43 : 7971-3.

Clouse SD. Plant development: a role for sterols in embryogenesis. Curr Biol 2000 ; 10 : R601-R604.

Collakova E, DellaPenna D. Homogentisate phytyltransferase activity is limiting for tocopherol biosynthesis in Arabidopsis. Plant Physiol 2003; 131 : 632-42.

Colombo ML. An update on vitamin E, tocopherol and tocotrienol-perspectives. Molecules 2010; 15 : 2103-13.

Crews C, Hough P, Godward J, et al. Study of the main constituents of some authentic hazelnut oils. J Agric Food Chem 2005a ; 53 : 4843-52.

Crews C, Hough P, Godward J, et al. Study of the main constituents of some authentic walnut oils. J Agric Food Chem 2005b ; 53 : 4853-60.

Dachtler MF, van de Put HM, von Stijn F, Beindorff $\mathrm{CM}$, Fritsche J. On-line LC-NMR-MS characterization of sesame oil extracts and assessment of their antioxidant activity. Eur / Lipid Sci Technol 2003; 105 : 488-96.

De Greyt WF, Petrauskaite V, Kellens MJ, Huyghebaert AD. Analysis of tocopherols by gas-liquid and high-performance liquid chromatography: a comparative study. Fett-Lipid $1998 ; 100$ : 503-7.

DellaPenna D, Pogson BJ. Vitamin synthesis in plants: tocopherols and carotenoids. Annu Rev Plant Biol $2006 ; 57: 711-38$.

Demonty I, Ras RT, van der Kniap HCM, et al. Continuous dose-response relationship of the LDLcholesterol-lowering effect of phytosterol intake. / Nutr 2009 ; 139 : 271-84.

Demurin Y, Skoric D, Karlovic D. Genetic variability of tocopherol composition in sunflower seeds as a basis of breeding for improved oil quality. Plant Breed 1996 ; 115 : 33-6.

Demurin YN, Efimenko SG, Peretyagina TM. Genetic identification of tocopherol mutations in sunflower. Helia 2004 ; 27 : 113-6.

Dolde D, Vlahakis C, Hazebroek J. Tocopherols in breeding lines and effects of planting location, fatty acid composition, and temperature during development. J Am Oil Chem Soc 1999 ; 76 : 349-55.

Ebrahimi A, Maury P, Berger M, et al. QTL mapping of seed-quality traits in sunflower recombinant inbred lines under different water regimes. Genome $2008 ; 51: 599-615$.

Eggeling C, Ringemann C, Medda R, et al. Direct observation of the nanoscale dynamics of membrane lipids in a living cell. Nature 2009 ; 457 : 1159-U121.

Falk J, Munne-Bosch S. Tocochromanol functions in plants: antioxidation and beyond. J Exp Bot 2010; $61: 1549-66$.

Fernandes P, Cabral JMS. Phytosterols: applications and recovery methods. Biores Technol 2007; 98 : 2335-50. 
Fernandez-Moya V, Martinez-Force E, Garces R. Temperature effect on a high stearic acid sunflower mutant. Phytochem $2002 ; 59$ : 33-7.

Fisk ID, White DA, Carvalho A, Gray DA. Tocopherolan intrinsic component of sunflower seed oil bodies. J Am Oil Chem Soc 2006 ; 83 : 341-4.

Folmer BM. Sterol surfactants: from synthesis to applications. Adv Coll Interf Sci 2003 ; 103 : 99-119.

Frandsen $\mathrm{Gl}$, Mundy J, Tzen J. Oil bodies and their associated proteins, oleosin and caleosin. Physiol Plant $2001 ; 112$ : 301-7.

Garcia-Moreno M], Vera-Ruiz EM, FernandezMartinez JM, Velasco L, Perez-Vich B. Genetic and molecular analysis of high gamma-tocopherol content in sunflower. Crop Sci 2006 ; 46 : 2015-21.

Goffman FD, Becker HC. Genetic variation of tocopherol content in a germplasm collection of Brassica napus L. Euphytic 2002 ; 125 : 189-96.

Gonzalez-Martin I, Hernandez-Hierro JM, Bustamante-Rangel M, Barros-Ferreiro N. Nearinfrared spectroscopy (NIRS) reflectance technology for the determination of tocopherols in alfalfa. Anal Bioanal Chem 2006 ; 386 : 1553-8.

Grille S, Zaslawski A, Thiele S, Plat J, Warnecke D. The functions of steryl glycosides come to those who wait: Recent advances in plants, fungi, bacteria and animals. Progr Lipid Res $2010 ; 49$ : 262-88.

Grusak MA, DellaPenna D. Improving the nutrient composition of plants to enhance human nutrition and health. Annu Rev Plant Physiol Plant Mol Biol 1999 ; 50 : 133-61.

Gul MK, Egesel CO, Tayyar S, Kahrman F. Changes in phytosterols in rapeseed (Brassica napus L.) and their interaction with nitrogen fertilization. Int I Agric Biol $2007 ; 9: 250-3$.

Hamama AA, Bhardwaj HL, Starner DE. Genotype and growing location effects on phytosterols in canola oil. J Am Oil Chem Soc 2003 ; 80 : 1121-6.

Hampshire J. Importance of unsaponifiable components in oat oil. Muhle + Mischfuttertechnik 1993; $130: 17-9$.

Harker M, Holmberg N, Clayton JC, et al. Enhancement of seed phytosterol levels by expression of an $\mathrm{N}$-terminal truncated Hevea brasiliensis (rubber tree) 3-hydroxy-3-methylglutaryl-CoA reductase. Plant Biotechnol / 2003 ; 1 : 113-21.

Hartmann MA. Plant sterols and the membrane environment. Trends Plant Sci 1998 ; 3 : 170-5.

Hass CG, Tang SX, Leonard S, Traber MG, Miller JF, Knapp SJ. Three non-allelic epistatically interacting methyltransferase mutations produce novel tocopherol (vitamin E) profiles in sunflower. Theor Appl Genet $2006 ; 113:$ 767-82.

Hey SJ, Powers SJ, Beale MH, Hawkins ND, Ward JL, Halford N. Enhanced seed phytosterol accumulation through expression of a modified HMG-CoA reductase. Plant Biotechnol / 2006 ; 4 : 219-29.

Hofius D, Sonnewald U. Vitamin E biosynthesis: biochemistry meets cell biology. Trends Plant Sci 2003 ; $8: 6-8$.
Hourant P, Baeten V, Morales MT, Meurens M, Aparicio R. Oil and fat classification by selected bands of near-infrared spectroscopy. Appl Spectr 2000 ; 54 : 1168-74.

Ibrahim KE, Juvik JA. Feasibility for improving phytonutrient content in vegetable crops using conventional breeding strategies: case study with carotenoids and tocopherols in sweet corn and broccoli. / Agric Food Chem 2009 ; 57 : 4636-44.

Izquierdo NG, Aguirrezabal LAN. Genetic variability in the response of fatty acid composition to minimum night temperature during grain filling in sunflower. Field Crops Res 2008 ; 106 : 116-25.

Izquierdo NG, Mascioli S, Aguirrezabal LAN, Nolasco $S M$. Temperature influence during seed filling on tocopherol concentration in a traditional sunflower hybrid. Grasas Y Aceites 2007 ; 58 : 170-8.

Karunanandaa B, Qi QG, Hao M, et al. Metabolically engineered oilseed crops with enhanced seed tocopherol. Metab Eng $2005 ; 7$ : 384-400.

Khallouki F, Spiegelhalder B, Bartsch H, Owen RW. Secondary metabolites of the argan tree (Morocco) may have disease prevention properties. Afr J Biotechnol $2005 ; 4: 381-8$.

Kriese U, Schumann E, Weber WE, Beyer M, Bruhl L, Matthaus B. Oil content, tocopherol composition and fatty acid patterns of the seeds of 51 Cannabis sativa L. genotypes. Euphytica 2004; 137 : 339-51.

Kurilich AC, Tsau G], Brown A, et al. Carotene, tocopherol, and ascorbate contents in subspecies of Brassica oleracea. J Agric Food Chem $1999 ; 47$ : 1576-81.

Lacombe S, Souyris I, Berville AJ. An insertion of oleate desaturase homologous sequence silences via siRNA the functional gene leading to high oleic acid content in sunflower seed oil. Mol Genet Genom. 2009.

Lagravere T, Kleiber D, Surel O, Calmon A, Bervill A, Dayd J. Comparison of fatty acid metabolism of two oleic and one conventional sunflower hybrids: a new hypothesis. J Agron and Crop Sci $2004 ; 190$ : 223-9.

Lampart-Szczapa E, Korczak J, Nogala-Kalucka M, Zawirska-Wojtasiak R. Antioxidant properties of lupin seed products. Food Chem $2003 ; 83: 279-85$.

Lampi AM, Kamal-Eldin A, Piironen V. Tocopherols and tocotrienols from oil and cereal grains. Functional Foods: Biochemical and Processing Aspect 2002; 2 : $1-38$.

Lechner M, Reiter B, Lorbeer E. Determination of free and esterified sterols in potential new oil seed crops by coupled on-line liquid chromatographygas-chromatography. Fett-Lipid $1999 ; 101$ : 171-7.

Leon L, Rallo L, Garrido A. Near-Infrared Spectroscopy (NIRS) analysis of intact olive fruit: an useful tool in olive breeding programs. Grasas $Y$ Aceites $2003 ; 54: 41-7$.

LiY, Wang ZN, Sun XF, Tang KX. Current opinions on the functions of tocopherol based on the genetic manipulation of tocopherol biosynthesis in plants. J Integr Plant Biol 2008 ; 50 : 1057-69.
Li Y, Zhou Y, Wang ZA, Sun XF, Tang KX. Engineering tocopherol biosynthetic pathway in Arabidopsis leaves and its effect on antioxidant metabolism. Plant Sci 2010; $178:$ 312-20.

Lichtenthaler HK. Biosynthesis, accumulation and emission of carotenoids, alpha-tocopherol, plastoquinone, and isoprene in leaves under high photosynthetic irradiance. Photosynth Res 2007; 92: 163-79.

Maatta K, Lampi AM, Petterson J, Fogelfors BM, Piironen V, Kamal-Eldin A. Phytosterol content in seven oat cultivars grown at three locations in Sweden. / Sci Food Agric $1999 ; 79$ : 1021-7.

Maeda H, Sage TL, Isaac G, Welti R, DellaPenna D. Tocopherols modulate extraplastidic polyunsaturated fatty acid metabolism in Arabidopsis at low temperature. Plant Cell $2008 ; 20: 452-70$.

Mantese Al, Medan D, Hall AJ. Achene structure, development and lipid accumulation in sunflower cultivars differing in oil content at maturity. Ann Bot 2006 ; 97 : 999-1010.

Marwede V, Schierholt A, Mollers C, Becker H. Genotype $\mathrm{X}$ environment interactions and heritability of tocopherol contents in canola. Crop Sci $2004 ; 44$ : 728-31.

Matthaus B, Bruhl L. Comparison of a supercritical fluid extraction method for the extraction of oilseeds with the DGF standard method B-I 5 (87). Fett-Lipid 1999 ; 101 : 203-6.

Mene-Saffrane L, DellaPenna D. Biosynthesis, regulation and functions of tocochromanols in plants. Plant Physiol Biochem $2010 ; 48$ : 301-9.

Mercau JL, Sadras VO, Satorre EH, et al. On-farm assessment of regional and seasonal variation in sunflower yield in Argentina. Agric Syst 2001; 67 : 83-103.

Moreau RA, Whitaker BD, Hicks KB. Phytosterols, phytostanols, and their conjugates in foods: structural diversity, quantitative analysis, and healthpromoting uses. Progr Lipid Res 2002; 41 : 457-500.

Moschner CR, Biskupek-Korell B. Estimating the content of free fatty acids in high-oleic sunflower seeds by near-infrared spectroscopy. Eur / Lipid Sci Technol $2006 ; 108: 606-13$.

Murphy DJ. Plant lipids: biology, utilisation and manipulation. Plant lipids: biology, utilisation and manipulation 2005; xvii : 403 p.

Ostlund RE, Racette SB, Stenson WF. Inhibition of cholesterol absorption by phytosterol-replete wheat germ compared with phytosterol-depleted wheat germ. Am J Clin Nutr 2003 ; 77 : 1385-9.

Palta JP, Whitaker BD, Weiss LS. Plasma-membrane lipids associated with genetic-variability in freezing tolerance and cold-acclimatation of solanum species. Plant Physiol $1993 ; 103$ : 793-803.

Peng LC, Kawagoe Y, Hogan P, Delmer D. Sitosterolbeta-glucoside as primer for cellulose synthesis in plants. Science $2002 ; 295$ : 147-50. 
Perez-Vich B, Garces R, Fernandez-Martinez JM. Inheritance of high palmitic acid content in the sunflower mutant CAS-12 and its relationship with high oleic content. Plant Breed 2002a ; 121 : 49-56.

Perez-Vich B, Garces R, Fernandez-Martinez JM. Inheritance of medium stearic acid content in the seed oil of a sunflower mutant CAS-4. Crop Sci 2002b ; 42 : 1806-11.

Perez-Vich B, Velasco L, Fernandez-Martinez JM. Determination of seed oil content and fatty acid composition in sunflower through the analysis of intact seeds, husked seeds, meal and oil by near-infrared reflectance spectroscopy. I Am Oil Chem Soc 1998 ; $75: 547-55$.

Peterson DM, Qureshi AA. Genotype and environment effects on tocols of barley and oats. Cereal Chem $1993 ; 70: 157-62$.

Phillips KM, Ruggio DM, Toivo Jl, Swank MA, Simpkins $\mathrm{AH}$. Free and esterified sterol composition of edible oils and fats. I Food Comp Anal 2002; 15 : 123-42.

Piironen V, Lindsay DG, Miettinen TA, Toivo J, Lampi AM. Plant sterols: biosynthesis, biological function and their importance to human nutrition. I Sci Food Agric 2000a ; 80 : 939-66.

Piironen V, Toivo J, Lampi AM. Natural sources of dietary plant sterols. J Food Comp Anal 2000b; 13 : 619-24.

Pleite R, Martinez-Force E, Garces R. Increase of the stearic acid content in high-oleic sunflower () seeds. J Agric Food Chem 2006 ; 54 : 9383-8.

Roche J, Alignan M, Bouniols A, et al. Sterol content in sunflower seeds (L.) as affected by genotypes and environmental conditions. Food Chem $2010 ; 121$ : 990-5.

Roche J, Bouniols A, Mouloungui Z, Barranco T, Cerny M. Management of environmental crop conditions to produce useful sunflower oil components. Eur) Lipid Sci Technol 2006 ; 108 : 287-97.

Ruiz RA, Maddonni GA. Sunflower seed weight and oil concentration under different post-flowering source-sink ratios. Crop Sci 2006 ; 46 : 671-80.

Salas IJ, Martinez-Force E, Garces R. Very long chain fatty acid synthesis in sunflower kernels. J Agric Food Chem $2005 ; 53: 2710-6$.

Salas IJ, Moreno-Perez AJ, Martinez-Force E, Garces R. Characterization of the glycerolipid composition of a high-palmitoleic acid sunflower mutant. Eur) Lipid Sci Technol 2007 ; 109 : 591-9.

Sánchez-Muniz F, Canales A, Librelotto J, Nus M. Phytosterols, a double-edged weapon? Grasas y Aceites $2004 ; 55: 321-7$.

Sanchez-Perez A, Delgado-Zamarreno MM, Bustamante-Rangel M, Hernandez-Mendez J. Automated analysis of vitamin $E$ isomers in vegetable oils by continuous membrane extraction and liquid chromatography-electrochemical detection. / Chromatogr A $2000 ; 881$ : 229-41.
Sato T, Maw AA, Katsuta M. NIR reflectance spectroscopic analysis of the FA composition in sesame (Sesamum indicum L.) seeds. I Am Oil Chem Soc $2003 ; 80$ : 1157-61.

Sato T, Maw AA, Katsuta M. Non-destructive nearinfrared reflectance spectroscopic analyses of the major constituents of SesamSesamum indicum L.) whole seeds with different coat color. Plant Prod Sci $2004 ; 7: 363-6$.

Sato T, Takahata Y, Noda T, Yanagisawa T, Morishita T, Sakai S. Non-destructive determination of fattyacid composition of husked sunflower (Helianthus annua $\mathrm{L}$ ) seeds by near-infrared spectroscopy. / Am Oil Chem Soc $1995 ; 72$ : 1177-83.

Sato T, Uezono I, Morishita T, Tetsuka T. Nondestructive estimation of fatty acid composition in seeds of Brassica napus L. by near-infrared spectroscopy. I Am Oil Chem Soc 1998 ; 75 : 1877-81.

Schaller $\mathrm{H}$. The role of sterols in plant growth and development. Progr Lipid Res $2003 ; 42$ : 163-75.

Schaller $\mathrm{H}$. New aspects of sterol biosynthesis in growth and development of higher plants. Plant Physiol Biochem 2004 ; 42 : 465-76.

Seppanen CM, Song QH, Csallany AS. The antioxidant functions of tocopherol and tocotrienol homologues in oils, fats, and food systems. I Am Oil Chem Soc $2010 ; 87: 469-81$.

Serrano-Vega MJ, Martinez-Force E, Garces R. Lipid characterization of seed oils from high-palmitic, low-palmitoleic, and very high-stearic acid sunflower lines. Lipids $2005 ; 40$ : 369-74.

Shimada TL, Hara-Nishimura I. Oil-body-membrane proteins and their physiological functions in plants. Biol Pharmaceut Bull 2010 ; 33 : 360-3.

Skoric D, Jocic S, Sakac Z, Lecic N. Genetic possibilities for altering sunflower oil quality to obtain novel oils. Canadian J Physiol Phamacol 2008 ; 86 : 215-21.

Stevenson DG, Eller FJ, Wang LP, Jane JL, Wang T, Inglett GE. Oil and tocopherol content and composition of pumpkin seed oil in 12 cultivars. J Agric Food Chem 2007 ; 55 : 4005-13.

Szlyk E, Szydlwska-Czerniak A, Kowalczyk-Marzec A. NIR spectroscopy and partial least-squares regression for determination of natural alpha-tocopherol in vegetable oils. J Agric Food Chem 2005; 53: 6980-7.

Talati R, Sobieraj DM, Makanji SS, Phung OJ, Coleman $\mathrm{Cl}$. The comparative efficacy of plant sterols and stanols on serum lipids: a systematic review and meta-analysis. / Am Diet Assoc 2010 ; 110 : 719-26.

Tammela P, Salo-Vaananen P, Laakso I, Hopia A, Vuorela $\mathrm{H}$, Nygren M. Tocopherols, tocotrienols and fatty acids as indicators of natural ageing in Pinus sylvestris seeds. Scandinav J Forest Res $2005 ; 20$ : 378-84.

Tang SX, Hass CG, Knapp SJ. Ty3/gypsy-like retrotransposon knockout of a 2-methyl-6-phytyl1,4-benzoquinone methyltransferase is non-lethal, uncovers a cryptic paralogous mutation, and produces novel tocopherol (vitamin E) profiles in sunflower. Theor Appl Genet 2006 ; 113 : 783-99.
Tasan M, Demirci M. Total and individual tocopherol contents of sunflower oil at different steps of refining. Eur Food ResTechnol $2005 ; 220$ : 251-4.

Traber MG. Vitamin E regulatory mechanisms. Annu Rev Nutr 2007 ; 27 : 347-62.

Trautwein EA, Duchateau G, Lin YG, Mel'nikov SM, Molhuizen HOF, Ntanios FY. Proposed mechanisms of cholesterol-lowering action of plant sterols. Eur J Lipid Sci Technol 2003 ; 105 : 171-85.

Velasco L, Fernandez-Martinez JM, Garcia-Ruiz R, Dominguez J. Genetic and environmental variation for tocopherol content and composition in sunflower commercial hybrids. J Agric Sci 2002 ; 139 : 425-9.

Velasco L, Perez-Vich B, Fernandez-Martinez JM. Non-destructive screening for oleic and linoleic acid in single sunflower achenes by near-infrared reflectance spectroscopy. Crop Sci $1999 ; 39$ : 219-22.

Velasco L, Perez-Vich B, Fernandez-Martinez JM. Novel variation for the tocopherol profile in a sunflower created by mutagenesis and recombination. Plant Breed 2004a ; 123 : 490-2.

Velasco L, Perez-Vich B, Fernandez-Martinez JM. Use of near-infrared reflectance spectroscopy for selecting for high stearic acid concentration in single husked achenes of sunflower. Crop Sci 2004b ; 44 : 93-7.

Vera-Ruiz EM, Velasco L, Leon AJ, FernandezMartinez J, Perez-Vich B. Genetic mapping of the Tph1 gene controlling beta-tocopherol accumulation in sunflower seeds. Mol Breed 2006; 17 : 291-6.

Verleyen T. Stability of minor components during vegetable oil refining. Applied biological sciences: chemistry. University of Gent. Gant 2002

Verleyen T, Forcades M, Verhe R, Dewettinck K, Huyghebaert A, De Greyt W. Analysis of free and esterified sterols in vegetable oils. J Am Oil Chem Soc 2002 ; 79 : 117-22.

Vlahakis C, Hazebroek J. Phytosterol accumulation in canola, sunflower, and soybean oils: effects of genetics, planting location, and temperature. I Am Oil Chem Soc $2000 ; 77: 49-53$.

Wagner KH, Isnardy B, Elmadfa I. Effects of seed damage on the oxidative stability of poppy seed oil. Eur J Lipid Sci Technol 2003 ; 105 : 219-24.

Warner K, Mounts TL. Analysis of tocopherols and phytosterols in vegetable oils by HPLC with evaporative light scattering detection. I Am Oil Chem Soc $1990 ; 67: 827-31$.

Weselake RJ, Taylor DC, Rahman MH, et al. Increasing the flow of carbon into seed oil. Biotechnol Adv 2009; $27: 866$-78.

Zacheo G, Cappello MS, Gallo A, Santino A, Cappello AR. Changes associated with post-harvest ageing in almond seeds. Food Sci Technol 2000 ; 33 : 415-23.

Zangenberg M, Hansen HB, Jorgensen JR, Hellgren LI. Cultivar and year-to-year variation of phytosterol content in rye (Secale cereale L.). J Agric Food Chem $2004 ; 52: 2593-7$.

Zappel NF, Panstruga R. Heterogeneity and lateral compartmentalization of plant plasma membranes. Curr Op Plant Biol $2008 ; 11$ : 632-40. 
Zheljazkov VD, Vick BA, Baldwin BS, Buehring N, Astatkie $T$, Johnson B. Oil content and saturated fatty acids in sunflower as a function of planting date, nitrogen rate, and hybrid. Agron / 2009 ; 101 : 1003-11.

Zlatanov MD, Angelova-Romova M], Antova GA, Dimitrova RD, Momchilova SM, NikolovaDamyanova BM. Variations in fatty acids, phospholipids and sterols during the seed development of a high oleic sunflower variety. I Am Oil Chem Soc $2009 ; 86: 867-75$.
NF EN ISO 659. Association française de normalisation, 1998. Norme européenne, NF EN ISO 659 d'octobre 1998; Norme française V 03-905: graines oléagineuses. Détermination de la teneur en huile (Méthode de référence). Afnor. Paris, 1998.

ISO 9936. International Standard Organization. ISO 9936: animal and vegetable fats and oilsDetermination of tocopherols and tocotrienols contents-Method using high-performance liquid chromatography. ISO. Genève, 1997.
NF EN ISO 12228. Association française de normalisation, European norm, NF EN ISO 12228 May 1999 ; French norm T 60-258 : animal and vegetable fats and oils-Determination of individual and total sterols contents-Gas chromatographic method. Afnor. Paris, 1999.

NF EN ISO 5508. Association française de normalisation, European norm, NF EN ISO 5508 juin 1995 ; French norm T60-234: Corps gras d'origines animale et végétale-Analyse par chromatographie en phase gazeuse des esters méthyliques d'acides gras. Afnor. Paris, 1995. 